a thorough investigation, visiting many foreign stations which have adopted preventive measures. In 46 of the 111 British selected stations no grit extraction plant has yet been installed. The subcommittee regards grading by sieves as unsatisfactory, as it is impossible when the mesh is too small and untrustworthy for larger values. Particles below 20 microns ( 1 micron is a thousandth part of a millimetre) when discharged into an air stream are sufficiently diffused to avoid creating a nuisance. The only satisfactory way of testing the efficiency of dust extraction plant is to weigh the dust in unit volume of the gases at as high a point in the chimney as practicable. In Germany, where the power stations are generally larger than in Great Britain, electrostatic precipitation together with very high chimneys is favoured. The main conclusions arrived at by the Committee are that dust nuisance is avoidable with new stations, but the application of means for its prevention to all existing stations may not be practicable. There is an urgent need for standardisation of good methods of testing dust extraction plant. For pulverised fuel installations the electrostatic precipitator is the most suitable type to use. Water for dust extraction is not to be com. mended. The minimum height of chimneys should be at least two and a half times that of the highest point of the generator station buildings. Photographs are given of the filters used for separating ash and grit particles and of plant for multiplecyclone dust extraction.

\section{Gaseous Tubes for Lighting}

THe study of the discharge of electricity through gases has led to many important practical developments, the latest being the invention of vacuum tubes for lighting. If discharge tubes are filled to the same gaseous pressure with different gases such as helium, neon, argon, hydrogen and nitrogen, it is found that a certain definite voltage must be applied to the terminals of the tube before luminous effects are produced. This voltage depends on the nature of the gas and the pressure in the tube. In general, neon produces a luminous effect at lower voltages than the other gases and then comes helium. In some cases a mixture of gases becomes luminous at a lower voltage than any of the pure gases forming it. In a lecture to the Preston Scientific Society given on December 2, 1932, J. N. Addington gave an interesting account of the progress made in developing gaseous tubes for lighting and signalling purposes. In an Osglim lamp, which takes only a small fraction of the power taken by a flament lamp, the electrodes are of nickel or iron placed about $2 \mathrm{~mm}$. apart and the neon gas filling has a definite low pressure. At 160 volts the lamp becomes luminous. These lamps operate from alternating current mains. Neon valves which operate traffic signal devices have now been developed at the Prestonlampworks of Messrs. Siemens Brothers and $\mathrm{Co}$. The red neon signs which are now familiar to all dwellers in cities have iron or nickel electrodes and the illumination is produced from the positive column. The intensity of illumina- tion per unit area is relatively low in these lamps, which are called cold cathode tubes. In 'hot cathode tubes' currents nearly a hundred times as great can be obtained. The electrodes are coated with mixtures of alkaline earths and have a very high electronic emission when heated to $1,200^{\circ} \mathrm{C}$. The use of metallic vapours like sodium, cadmium and magnesium has still further increased the efficiency of these tubes, but the colours at present obtained leave much to be desired when compared with daylight.

\section{Gifts to Science}

Sir Dugald Clerk, who died on November 12 (see NATURE of December 24, p. 953), bequeathed $\mathfrak{1 3 , 0 0 0}$ to the Institution of Civil Engineers ; $£ 2,000$ to the Royal Society ; $£ 1,000$ to the Royal Institution; $£ 1,000$ to the Royal Society of Arts; $£ 1,000$ to the Institution of Mechanical Engineers; $£ 1,000$ to the University of Glasgow; $£ 1,000$ to the University of Leeds; $\mathfrak{f 1 , 0 0 0}$ to the University of St. Andrews ; $£ 1,000$ to the University of Manchester; $£ 1,000$ to the University of Liverpool. The residue of the property is to be divided into thirty-one parts ; three of these parts are to go to the Institution of Civil Engineers; two to the Royal Society; one to the Royal Institution; one to the Royal Society of Arts ; one to the Institution of Mechanical Engineers ; and one each to the Universities of Glasgow, Leeds, St. Andrews, Manchester, and Liverpool.

\section{Entomological Society of London}

THe Entomological Society of London will celebrate its hundredth anniversary on May 3, and a preliminary programme of the centenary celebrations on May 3-4 has recently been published. On May 3, a general meeting will be held in the rooms of the Royal Geographical Society at 3 P.M. and a scientific conversazione at 8.30 P.M. A reception has been arranged for May 4 at 9.30 P.M. This will be held at Lancaster House, St. James's, S.W.I, when the Right Hon. Walter Elliot, Minister of Agriculture and Fisheries, will receive the guests. Further information can be obtained from the Secretary, 41 Queen's Gate, London, S.W.7.

\section{Chadwick Public Lectures}

THe next series of Chadwick Public Lectures begins on February 21, with a discourse on "The Hippocratic Tradition" by Dr. Matthew B. Ray. The lecture will be given in the hall of the Royal Society of Tropical Medicine, 26 Portland Place, W.1, at 5.15. The second lecture will be given by Dr. E. Killick Millard on "Housing", on March 9 at 8 P.M. at the Royal Sanitary Institute. How to secure a pure milk supply is the question chosen by Dr. J. Walter Carr, for his lecture- "Cows' Milk" in March at the Royal Society of Tropical Medicine. In it, he will discuss the relative benefits of human and bovine milk for infants, the value of milk in adult life and how to render cows' milk a safe food. In May, Mr. P. W. Coombe will lecture on "Port of London Sanitary Administration". The actual processes and details of the organisation and maintenance of port and river hygiene will be discussed. Another lecture 